\title{
Ağrilı total diz protezinde değerlendirme ve yönetim
}

\author{
Assessment and management of painful total knee prosthesis
}

\author{
Illhan Özkan
}

Özel Medinova Hastanesi, Ortopedi ve Travmatoloji Kliniği, Aydın

\begin{abstract}
Total diz protezi, gonartroz tedavisinde çok iyi klinik ve fonksiyonel sonuçlar vermesine karşın, hastaların yaklaşık \% 20 'sinde cerrahi sonrasında değişik derecelerde ağrı yakınması görülür. ilk yapılacak işlem, sistematik ve dikkatli bir inceleme ile bu ağrının nedeninin ortaya konulmasıdır. Bu incelemede; hastanın ayrıntılı öyküsü alınmalı, ağrının tipi analiz edilmeli, hastanın psikolojik durumu değerlendirilmeli, iyi bir fizik muayene ve laboratuvar testleri yapılmalı, gerekirse eklem aspirasyonu ve lokal enjeksiyonlar uygulanmalı, radyolojik tetkikler ve özel görüntüleme yöntemleri ile bir sonuca ulaşılmaya çalışılmalıdır. Bu incelemelerin ardından, hastada ağrıya neden olan patoloji ortaya konulmalı ve gereken tedaviye başlanmalıdır. Ağrının nedeni tam olarak ortaya konulmadan revizyon cerrahisinden kesinlikle kaçınılmalıdır.
\end{abstract}

Anahtar sözcükler: total diz protezi; ağrı; komplikasyonlar
Total knee arthroplasty has excellent clinical and functional results in patient with severe gonarthrosis; however, $20 \%$ of the patients continue to experience pain following total knee arthroplasty. Systematic and careful evaluation is needed to find the main cause of pain in these patients. The evaluation of the painful knee includes an extended history, analysis the type of the pain, psychological exploration, thorough clinical examination, laboratory tests, joint aspiration if needed, test infiltrations, radiographic analysis and special imaging techniques. Using these diagnostic modalities we try to find the reason of the pain and appropriate treatment for the patient. Revision surgery should not be performed before the causative pain mechanism is well understood.

Key words: total knee arthroplasty; pain; complications leri evre gonartroz tedavisinde total diz protezi (TDP) çok iyi sonuçlar vermesine karşın, hastaların \%20'sinde ağrı şikâyeti devam etmekte, bu da ortopedisti memnun olmayan hastalar ile karşı karşıya bırakmaktadır. ${ }^{[1-3]}$ Bu ağrının nedeninin ortaya konulması ve tedavisi dikkatli ve sistematik bir değerlendirme gerektirir. TDP sonrasında hastanın memnuniyeti pek çok faktöre bağlıdır. Cerrahi teknik ile ilgili konular ağrı nedeni olabileceği gibi, cerrahın kontrolünde olmayan faktörler de mevcuttur. Özellikle ameliyat öncesi dönemde ameliyat sonrası süreç hakkında iyi bilgilendirilmemiş hastalarda TDP'den beklentilerin fazla olması, hasta memnuniyetini azaltacak ve hissedilen ağrııı arttıracaktır.

Bilindiği gibi, ağrı vücudun bir savunma mekanizmasıdır. TDP sonrasında hissedilen ağrı hastanın yaşam kalitesini azaltır. Ağrı her hastaya göre değişen bir kavramdır. Uluslararası Ağrı Araştırmaları Derneği (IASP) ağrıyı, organik ya da organik olmayan bir nedenle ortaya çıkan ve duyusal ya da duygusal bakımdan hoş olmayan bir deneyim olarak tanımlar. ${ }^{[4]}$ Ağrı vücuttaki birden fazla organ sistemini ilgilendiren, çok faktörlü, karmaşık mekanizmaların etkin olduğu bir deneyimdir. Bu karmaşık problemi daha iyi anlayabilmek için temel olarak iki tip ağrı olduğunu bilmemiz gerekir. Nosiseptif ağrı, sinir dokusu dışındaki bir dokunun hasarı sonrasında nosiseptörlerin aktivasyonu ile ortaya çıkar. Nosiseptif ağrı, viseral veya somatik ağrı olarak tanımlanır. Somatik ağrı deri, kas, eklem kapsülü, kemik gibi dokulardan kaynaklanır. Nöropatik ağrı ise somatosensör sinir sisteminde bir lezyon ya da hastalık sonucunda ortaya çıkar. Bir sinirin yaralanması, tümörler, toksinler, metabolik hastalıklar, enfeksiyon, primer nörolojik hastalıklar, nöropatik ağrının temel nedenleridir. Nosiseptif ağrı nonsteroid anti-inflamatuvar ve opioid ilaçlara yanıt verirken, nöropatik ağı antiepileptik, antidepresan ve lokal anestezik ilaçlara daha iyi yanıt verir. ${ }^{[5,6]}$

- Illetişim adresi: Prof. Dr. İlhan Özkan, Özel Medinova Hastanesi, Efeler Mah. İzmir Blv. No: 82, Aydın

Tel: 0532 - 5065151 e-posta: iozkan@superonline.com

- Geliș tarihi: 19 Aralık 2018 Kabul tarihi: 19 Aralık 2018 


\section{AĞRILI DIZDE AYIRICI TANI}

TDP sonrasında ağrıya neden olan patolojiler temel olarak ekstrensik ve intrensek faktörler olarak iki ana gruba ayrılır (Tablo 1 ve 2). ${ }^{[7]}$ Bunlar içerisinde ağrı nedeni olarak en sık karşımıza çıkanlar enfeksiyon, instabilite, patellofemoral problemler, osteoliz ve protezin gevşemesidir. ${ }^{[7]}$

\section{Ağrılı TDP'nin Değerlendirilmesi}

Ağrılı TDP ile gelen hastalarda bütün nedenler gözden geçirilmeli, dikkatli ve ayrıntılı değerlendirme yapılmalıdır. Bu değerlendirme sırasında gerektiğinde fizik tedavi ve algoloji uzmanlarından da destek alınmalıdır. Cerrahi girişim ile ilgili ağrıya neden olabilecek faktörlerin ayrılması en önemli konudur. Bu faktörler, temel olarak Tablo 2'de TDP sonrasında ağrıya neden olabilecek intrensek faktörler başlığında sıralanan faktörlerdir. İntrensek faktörler bu sayıdaki diğer bölümlerde ayrıntılı olarak gözden geçirilmiştir.

TDP ameliyatından sonra uygun analjeziklerin kullanımı, hastanın ağrısız bir erken ameliyat sonrası dönem geçirmesi açısından önemlidir. TDP sonrasında hastaların çoğunda ilk üç aylık süreç içerisinde bir miktar ağrı mevcuttur. Daha küçük bir hasta grubunda ise ameliyattan üç ay sonra da ağrı olabilir. Hastalar, ameliyat sonrasında bu kadar uzun süre ağrı kesici kullanmamaları gerektiğini düşünerek ağıı kesici kullanımını sonlandırabilirler. Ağrının devam etmesinin temel nedeni bu olabilir. Ağrının devam etmesi, eklem hareket açıklığının istenilen düzeye ulaşmamasına, buna ikincil eklem sertliğine neden olabilir. Bu yüzden, ağrı kesici kullanımı konusunda hasta uyarılmalı ve hastanın uygun doz ve süre ağrı kesici kullanması sağlanmalıdır. Burada yapılmaması gereken hata, ağrı kesici kullanıldığı için, ağrıya neden olan bir intrensek faktörün atlanmasıdır. Bu yüzden, özellikle TDP sonrasındaki ilk altı aylık süreçte hastanın uygun analjezikler kullanması sağlanmalı ama ağıısı devam eden hastalarda ağrı nedeni olabilecek intrensek nedenler de gözden kaçırılmamalıdır.

\section{Öykü ve Fizik Muayene}

Öykü ve fizik muayene, TDP sonrasında ağrı şikâyeti olan olgularda en kritik aşamalardan biridir. Ağrının nedenini bulmak ve tedavi planı için yolumuzu belirlerken ilk ipuçlarını öykü ve fizik muayeneden alırız. Illk olarak hastanın primer semptomunun ne olduğu ortaya konulmalıdır; hastanın temel yakınması ağrı $\mathrm{m}$, instabilite mi, eklem şişliği mi, eklem sertliği mi? ${ }^{[8]}$ Öyküde TDP'nin yapıldığı tarih, nerede yapıldığı, ne cins bir implant kullanıldığı öğrenilmelidir. Eğer elde edilebiliyorsa, hastanın ameliyat raporu, ameliyat
Tablo 1. TDP sonrasında ağrıya neden olabilecek ekstrensik faktörler ${ }^{[7]}$

\begin{tabular}{ll}
\hline I. & Kalça eklemine ait patolojiler \\
II. & Nörolojik nedenler \\
a. & Spinal stenoz ve disk hastalıkları \\
b. & Nöroma \\
c. & Kompleks bölgesel ağrı sendromu \\
III. & Vasküler nedenler; derin ven trombozu, vasküler kladikasyo \\
IV. & Pes anserinus bursiti \\
V. & Stres kırı̆̆ı ve periprostetik kırık \\
VI. & Tendinopati (patellar/kuadriseps) \\
VII. & Heterotopik ossifikasyon \\
VIII. & Psikolojik hastalıklar \\
IX. & Diğer \\
a. & Paget hastalı̆̆ı \\
b. & Pigmente villonodüler sinovit \\
c. & Romatoid artrit \\
d. & Ayak ve ayak bileği patolojileri
\end{tabular}

Tablo 2. TDP sonrasında ağrıya neden olabilecek intrensek faktörler ${ }^{[7]}$

\begin{tabular}{|c|c|}
\hline I. & Enfeksiyon \\
\hline a. & Erken ameliyat sonrası enfeksiyon \\
\hline b. & Akut hematojen enfeksiyon \\
\hline c. & Geç kronik enfeksiyon \\
\hline II. & İnstabilite \\
\hline a. & Mediolateral \\
\hline b. & Anteroposterior \\
\hline c. & Fleksiyon/ekstansiyon \\
\hline III. & Dizilim bozukluğu \\
\hline a. & Koronal düzlem \\
\hline b. & Sagittal düzlem \\
\hline c. & Rotasyonel \\
\hline IV. & Yumuşak doku sıkışması \\
\hline a. & Patellar klank \\
\hline b. & Fabellar sıkışma \\
\hline c. & Popliteal tendon sıkışması \\
\hline d. & Büyük, taşan komponentler \\
\hline V. & Artrofibrozis \\
\hline VI. & Aşınma, osteoliz ve aseptik gevşeme \\
\hline VII. & Tekrarlayan hemartrozlar \\
\hline VIII. & Ekstansör mekanizma problemleri \\
\hline a. & Patellar maltraking \\
\hline b. & $\begin{array}{l}\text { Ekstansör mekanizma yaralanmaları (patella kırı̆ı, } \\
\text { patellar ve kuadriseps tendon yaralanmaları) }\end{array}$ \\
\hline c. & Patellar komponent kullanılmaması \\
\hline d. & Patellar komponentin büyük ve kalın olması \\
\hline e. & Patella baja ve patella alta \\
\hline
\end{tabular}


öncesi ve erken ameliyat sonrası dönemde çekilen direkt grafileri değerlendirilmelidir. Hastanın erken ameliyat sonrası dönemde, yapılan ameliyat ile ilgili bir sorun yaşayıp yaşamadığı, hastanede kalış süresi ve ameliyat sonrasında rehabilitasyon sürecinde yapılanlar öğrenilmelidir. Ağrı ne kadar zamandır var, ağrının lokalizasyonu tam olarak neresi, ağrının istirahat ve hareketle ilişkisi ne, ağrı ne kadar sürüyor, ağrının azalmasını ve artmasını sağlayan faktörler nelerdir, ağrının derecesi ne, günlük yaşam kalitesini etkileyen bir ağrı var mı soruları cevaplanmalıdır. Bu cevaplar bize yol gösterici olacaktır. Ağrılı bir TDP olgusu ile karşılaşıldığında akla ilk gelmesi gereken konu enfeksiyondur. Bazı cerrahlar, aksi ispatlanıncaya kadar ağrılı TDP'nin enfeksiyon olarak kabul edilmesi gerektiğini savunurlar. Özellikle, ameliyat sonrasındaki ilk bir yıl içerisinde enfeksiyon olasılığı daha yüksektir. Bunun yanında diğer nedenler -aşınma, osteoliz ve gevşeme- de değerlendirilmelidir. Bir yıldan sonra başlayan ağrılarda ise, öncelikle aşınma, osteoliz ve gevşeme, ardından enfeksiyon düşünülmelidir. Hastanın ameliyatından önce var olan ve ameliyattan sonra da benzer şekilde devam eden ağrı sıklıkla ekstrensik bir nedene bağlı ağrıdır. Tablo 3'te ağrının özelliğine göre ilk akla gelmesi gereken nedenler sıralanmıştır. ${ }^{[9]}$ Aktivite ile artan ağrı mekanik nedenleri düşündürürken, istirahat ve aktivite değişikliği ile geçmeyen ağrı ilk planda enfeksiyonu düşündürür. Beraberinde ateş ve döküntü gibi ek bulgular olan ağrı, enfeksiyonu akla getirir.

Tablo 3. Ağrı tipi ve nedeni[9]

\begin{tabular}{|c|c|}
\hline \multirow[t]{2}{*}{ Gece ve istirahat ağrısı } & Enfeksiyon \\
\hline & $\begin{array}{l}\text { Eklemde effüzyon veya } \\
\text { nörojenik }\end{array}$ \\
\hline \multirow{2}{*}{$\begin{array}{l}\text { Sandalyeden kalkarken ve } \\
\text { merdiven inerken ağrı }\end{array}$} & Fleksiyon instabilitesi \\
\hline & Femurda malrotasyon \\
\hline \multirow[t]{2}{*}{ Diz önü ağrısı } & Patellofemoral ağrı \\
\hline & Tendinit veya nöroma \\
\hline \multirow[t]{2}{*}{ Dizin arka kısmında ağrı } & Posterior dokularda gerginlik \\
\hline & Popliteal tendinit \\
\hline \multirow[t]{2}{*}{ Tam ekstansiyonda ağrı } & $\begin{array}{l}\text { Anteriorda yumuşak doku } \\
\text { sıkışması }\end{array}$ \\
\hline & Posterior gerginlik \\
\hline \multirow[t]{2}{*}{ Tam fleksiyonda ağrı } & Posterior sıkışma \\
\hline & $\begin{array}{l}\text { Patellada sıkışma veya } \\
\text { gerginlik }\end{array}$ \\
\hline \multirow{3}{*}{$\begin{array}{l}\text { Hareket başlangıcında ağrı } \\
\text { Yük verince olan ağrı }\end{array}$} & Komponent gevşemesi \\
\hline & Mekanik nedenler \\
\hline & Nonspesifik \\
\hline
\end{tabular}

Aktivite ile artan, tekrarlayan şişmelerin eşlik ettiği ağrılarda, instabilite akla gelmelidir. Yanıcı, elektrik çarpması gibi, saplanır tarzda, sıkılma şeklinde hissedilen, spazm ve soğukluk hissetme ile beraber olan ağrılarda, nöropatik köken akla gelmelidir. Uyluk ve ayağa yayılan ağrılarda, ağrının lomber vertebralardan köken alabileceği unutulmamalıdır.

Ağrılı TDP ile gelen bir hastada dikkatli bir fizik muayene yapılmalıdır. Alt ekstremitelerin tümü soyularak gözlenmeli, hastanın vital bulguları, boyu, kilosu, yürüyüşü, genel görünüşü değerlendirilmelidir. Ciltteki lezyonlar, şişlik, kızarıklık, ısı artışı, sinus ağzı araştırılmalıdır. Hasta yürürken, diz ekleminin varus ya da valgusa kaçması, Trendelenburg bulgusu varlığı gözlenmelidir. Aktif ve pasif eklem hareket açıklıkları ölçülmeli, özellikle ekstansiyon kısıtlılığının varlığı değerlendirilmelidir. Varus ve valgus stres testi yapılmalı, arka çekmece testi değerlendirilmelidir. Hastanın kendi kuvveti ile bacağını kaldırması istenmeli, kas atrofileri varsa not edilmelidir. Diz palpe edilerek şişlik, effüzyon ve lokal hassasiyet varlığı araştırılmalıdır. iliotibial bant ve pes anserinus boyunca olabilecek hassasiyet araştırılmalıdır.

TDP sonrasında patellanın önemli ağıı nedenlerinden biri olduğu hep akılda tutulmalı ve patellofemoral eklem dikkatlice muayene edilmelidir. Patellar klank senromu, patellar komponentin küçük ya da büyük kullanılmış olması, patellar tendon kısalığı, femoral komponentin küçük kullanılması, kalın tibial polietilen kullanılması, femoral komponentin fleksiyonda konulması patellofemoral ağrı nedeni olabilir. ${ }^{[10]}$

Ekstremitenin nörovasküler muayenesi mutlaka yapılmalıdır. Fizik muayenede omurga, kalça, ayak ve ayak bileği patolojileri de değerlendirilerek ekstrensik nedenler ekarte edilmeye çalışılmalıdır.

\section{Görüntüleme}

Ağrılı TDP değerlendirmesinde, iyi kalitede basarak ön-arka, yan, tanjansiyel patella ve alignment grafilerinin çekilmesi görüntülemede ilk yapılacak tetkiklerdir. Bu grafilerden, alt ekstremitenin varus ya da valgus diziliminde olduğunu, komponent boylarını ve taşmaları, komponent gevşemesini, radyolüsen çizgileri, osteolizi, polietilen aşınmasını (eklem aralığı kaybı ya da eşit olmayan eklem aralıkları), heterotopik ossifikasyonları değerlendirmek mümkündür. Yan grafilerde; femoral komponentin büyüklüğü, öne translasyonu, patellanın yetersiz rezeksiyonu, patellanın eklem çizgisine göre yeri kolaylıkla görülür. Tanjansiyel grafiler, patellofemoral eklemi değerlendirmek açısından önemlidir. Patellanın yerleşim bozuklukları, patellar tilt, kırık ve radyolüsen çizgiler görülebilir. 
Bilgisayarlı tomografi (BT) veya metal artefaktın azaltıldığı manyetik rezonans (MR) görüntüleme ağrılı TDP'de kullanılabilecek diğer yöntemlerdir. Bu tetkikler femoral ve tibial komponentin rotasyonel değerlendirilmesi için kullanılır. Femoral komponentin rotasyonu transepikondiller aksa göre, tibial komponentin rotasyonu tuberositas tibianın 1/3 mediyal kısmı esas alınarak değerlendirilir. Her iki komponentin internal rotasyonu, patellar instabilite veya lateral fleksiyon laksitesine, bunlar da ağrıya neden olur.

Kemik sintigrafisi; aseptik gevşeme, enfeksiyon ve stres kırıklarının değerlendirilmesinde önemlidir. Kemik sintigrafisi nonspesifik bir tetkiktir ve özellikle ameliyat sonrası ilk iki yıl içerisinde yalancı pozitiflik oranı yüksektir. TDP sonrası birinci yılda tibial komponentlerin \%90'ında ve femoral komponentlerin \%65'inde teknesyum ile yapılan kemik sintigrafisinde artmış tutulum gözlenir. ${ }^{[11]}$ Teknesyum sintigrafisi ile septik ve aseptik gevşeme ayrımı yapmak mümkün değildir. İndium 111 işaretli sintigrafiler negatif olduğu zaman enfeksiyon ekarte edilebilir; fakat bu tetkikin yüksek oranda yalancı pozitif sonuçlar verdiği unutulmamalıdır. ${ }^{12,13]}$ Enfeksiyon değerlendirmesi amacı ile pozitron emisyon tomografisi (PET) de kullanılabilir. ${ }^{[14]}$

\section{Laboratuvar İncelemeleri}

TDP'de revizyon nedenleri arasında ilk sırada enfeksiyon gelmektedir; bu yüzden ağrılı TDP'de ayırıcı tanıda enfeksiyon mutlaka ekarte edilmelidir. ${ }^{[15]}$ Sedimentasyon, C-reaktif protein (CRP), aspire edilen eklem sıvısında hücre sayımı ve kültür enfeksiyon tanısı için önemli incelemelerdir. Bu konudaki ayrıntılı inceleme ve yapılacak diğer laboratuvar incelemeleri "Derin Enfeksiyon" bölümünde ayrıntılı olarak anlatılmıştır.

Laboratuvar incelemelerinin, TDP sonrasında ağrının nedeninin araştırılmasında etiyolojik faktör olarak enfeksiyon dışındaki konularda bize katkısı çok sınırıdır.

\section{Açıklanamayan Ağrı}

Tüm çabalarımıza rağmen bir kısım hastada ağıının nedeninin açıklanması mümkün olmayabilir. Hatta bu hastaların aktiviteleri ve eklem hareket açıkıkları beklenen sınırlarda olabilir. Bazı hastalar hareket ettikleri zaman rahat ettiklerini, sabit kaldıkları zaman ağrılarının olduğunu belirtirler. Komponent yerleşiminde bir hata olmasa da, bunun nedeni sınırlı miktardaki fleksiyon kontraktürü ve eklem hareket açıklığındaki minimal kısitlılık olabilir. Her 300 diz protezi olgusundan birinde bu tür bir yakınma olabileceği bildirilmiştir. ${ }^{[16]}$ Bu hastalarda gerçek nedenin ne olduğunu bulmak zordur; refleks sempatik distrofi, düşük gradeli enfeksiyonlar, metal alerjisi gibi çok nadir görülen durumlar da akla getirilmelidir. ${ }^{[16]}$ Hiçbir nedenin bulunamadığı ağrılı dizlerde skopi ile tam yan ve tam ön-arka grafiler elde edilerek aseptik gevşemenin gösterilebileceği belirtilmiştir. ${ }^{[17]}$ Bu hastaların skopi kullanılmadan çekilmiş olan ön-arka ve yan grafileri normal olarak değerlendirilmiştir. ${ }^{[17]}$

Nedeni açıklanamayan ağrısı olan olguların bazılarında, ağrının lokalizasyonuna göre lokal enjeksiyonlar yapılabilir. Lokal anestezikler ve kortizon kullanılarak yapılabilecek bu enjeksiyonlar hem tanı hem de tedavi konusunda cerraha yardımcı olabilir.

Tüm yapılan incelemelere karşın ağrının nedeninin bulunamadığı olgularda revizyon kararı vermek çok güçtür. Bu hastalarda yapılacak revizyonların da benzer sonuçlar verebileceği unutulmamalıdır. Açıklanamayan ağrııı bu tür olguların bir kısmında yumuşak dokuların, menisküslerden kalan parçaların sıkışmaya neden olabileceği de akla getirilmelidir. Yumuşak dokulardaki bu patolojiler artroskopik cerrahi ile tedavi edilebilir, bu dizlerde artroskopi yaparak yumuşak dokularda sıkışma gibi bir patolojinin ortaya konulması ve tedavisi mümkündür. Artroskopi bizi daha büyük bir cerrahiden koruyacaktır. ${ }^{[16]}$

Açıklanamayan ağrısı olan TDP'li hastalarda yansıyan ağrı, lomber nedenler, patellar klank sendromu, patellanın lateral faset irritasyonu, kalan osteofitlerin ya da kalan sement parçalarının irritasyonu, popliteal tendon disfonksiyonu, mediyale taşma sonucu mediyal irritasyon gibi az görülen ve az akla gelen nedenler bir kez daha gözden geçirilmelidir. Malign primer bir tümörün ya da metastazın ağıı nedeni olabileceği unutulmamalıdır. ${ }^{[18]}$

\section{SONUÇ}

Ağrılı TDP olan olgularda önemli olan, ağrının nedeninin ortaya konulabilmesidir. Intrensek ve ekstrensik faktörler dikkatlice incelenerek bir sonuca ulaşılmaya çalışır. Tarihsel süreç içerisinde TDP sonrasında ağrı ve başarısızlık nedenleri; aseptik gevşeme, instabilite ve dizilim bozukluğu olarak belirtilmiştir. ${ }^{[19]}$ Polietilen teknolojisindeki gelişmeler, polietilen aşınması ve buna bağlı osteoliz gelişme oranını çok azaltmıştır; günümüzde enfeksiyon, gevşeme ve instabilite en çok görülen revizyon nedenleridir. ${ }^{[19]}$ Ağrının nedeni ortaya konulduktan sonra, tedavi cerrah için kolay olacaktır. Ağrılı bir TDP'de temel prensip, ağrının nedeni ortaya konulmadan revizyon gibi majör bir cerrahinin yapılmasına karar verilmemesi gerektiğidir. Sorunun ne olduğunu tam olarak bilmeden yapılacak bir cerrahi, hem hastayı ve cerrahı mutlu etmeyecek hem de yeni sorunların oluşmasına zemin hazırlayacaktır. ${ }^{[20]}$ 


\section{KAYNAKLAR}

1. Bonnin MP, Basiglini L, Archbold HA. What are the factors of residual pain after uncomplicated TKA? Knee Surg Sports Traumatol Arthrosc 2011;19(9):1411-7. Crossref

2. Lingard EA, Riddle DL. Impact of psychological distress on pain and function following knee arthroplasty. J Bone Joint Surg Am 2007;89(6):1161-9. Crossref

3. Scott C, Howie CR, MacDonald D, Biant LC. Predicting dissatisfaction following total knee replacement: a prospective study of 1217 patients. J Bone Joint Surg $\mathrm{Br}$ 2010;92-B(9):1253-8. Crossref

4. Merskey $\mathrm{H}$, Bugduk N, editors. Classification of chronic pain. Descriptions of chronic pain syndrome and definition of pain terms, 2nd ed. Seattle (WA): IASP Press; 1994.

5. Arner S, Meyerson BA. Lack of analgesic effect of opioids on neuropathic and idiopathic forms of pain. Pain 1988;33(1):11-23. Crossref

6. Covington EC. Anticonvulsants for neuropathic pain and detoxification. Cleve Clin J Med 1998;65(Suppl 1):S1-21-30. Crossref

7. Mandalia V, Eyres K, Schranz P, Toms AD. Evaluation of patients with a painful knee replacement. J Bone J Surg Br 2008;90-B(3):265-71. Crossref

8. Cercek R, Bassett RB, Myerthall S. Evaluation of the painful total knee arthroplasty. J Knee Surg 2015;28(2):113-8. Crossref

9. Hofmann S, Seitlinger G, Djahani O, Pietsch M. The painful knee after TKA: a diagnostic algorithm for failure analysis. Knee Surg Sports Traumatol Arthrosc 2011;19(9):1442-52. Crossref

10. Dennis DA, Kim RH, Johnson DR, Springer BD, Fehring TK, Sharma A. Control-matched evaluation of painful patellar Crepitus after total knee arthroplasty. Clin Orthop Relat Res 2011;469(1):10-7. Crossref

11. Hofmann AA, Wyatt RW, Daniels AU, Armstrong L, Alazraki $\mathrm{N}$, Taylor A Jr. Bone scans after total knee arthroplasty in asymptomatic patients. Cemented versus cementless. Clin Orthop Relat Res 1990;(251):183-8. Crossref
12. Rand JA, Brown ML. The value of indium 111 leukocyte scanning in the evaluation of painful or infected total knee arthroplasties. Clin Orthop Relat Res 1990;(259):179-82. Crossref

13. Scher DM, Pak K, Lonner JH, Finkel JE, Zuckerman JD, Di Cesare PE. The predictive value of indium-111 leukocyte scans in the diagnosis of infected total hip, knee, or resection arthroplasties. J Arthroplasty 2000;15(3):295-300. Crossref

14. Basu S, Kwee TC, Saboury B, Garino JP, Nelson CL, Zhuang $H$, Parsons $M$, Chen W, Kumar R, Salavati A, Werner TJ, Alavi A. FDG PET for diagnosing infection in hip and knee prostheses: prospective study in 221 prostheses and subgroup comparison with combined (111) In-labeled leukocyte/(99m) Tc-sulfur colloid bone marrow imaging in 88 prostheses. Clin Nucl Med 2014;39(7):609-15. Crossref

15. Bozic KJ, Kurtz SM, Lau E, Ong K, Chiu V, Vail TP, Rubash HE, Berry DJ. The epidemiology of revision total knee arthroplasty in the United States. Clin Orthop Relat Res 2010;468(1):4551. Crossref

16. Khakharia S, Nett MP, Hajnik CA, Scuderi GR. Complications of Total Knee Arthroplasty. In: Scott WN, Editor. Surgery of the Knee. Philadelphia: Elsevier; 2018. pp.1858-83.

17. Fehring TK, McAvoy G. Fluoroscopic evaluation of the painful total knee arthroplasty. Clin Orthop Relat Res 1996;331:22633. Crossref

18. Allain J, Le Mouel S, Voiçin MC, Delepine G, Goutallier D. The importance of systematic histological examination after loosening of an implant. J Bone Joint Surg Br 1998;80$B(4): 591-4$. Crossref

19. Lum ZC, Shieh AK, Dorr LD. Why total knees fail -A modern perspective review. World J Orthop 2018;9(4):60-4. Crossref

20. McDowell M, Park A, Gerlinger TL. The painful total knee arthroplasty. Orthop Clin North Am 2016;47(2):317-26. Crossref 